\title{
Anti-inflammatory and antitumor action of hydrogen via reactive oxygen species (Review)
}

\author{
YE YANG, YAPING ZHU and XIAOWEI XI \\ Department of Obstetrics and Gynecology, Shanghai General Hospital, \\ Shanghai Jiao Tong University School of Medicine, Shanghai 200080, P.R. China
}

Received November 19, 2017; Accepted June 20, 2018

DOI: $10.3892 / \mathrm{ol} .2018 .9023$

\begin{abstract}
Hydrogen $\left(\mathrm{H}_{2}\right)$ has advantages that lead it to be used as a novel antioxidant in preventive and therapeutic applications. $\mathrm{H}_{2}$ can permeate into biomembranes, cytosol, mitochondria and nuclei, and can be dissolved in water or saline to produce $\mathrm{H}_{2}$ water or $\mathrm{H}_{2}$-rich saline. $\mathrm{H}_{2}$ selectively reduces oxidants of the detrimental reactive oxygen species (ROS), including hydroxyl radicals $(\cdot \mathrm{OH})$ and peroxynitrite $\left(\mathrm{ONOO}^{-}\right)$, which serve a causative role in the promotion of tumor cell proliferation, invasion and metastasis, but do not disturb metabolic oxidation-reduction reactions in cell signaling. Compared with traditional antioxidants, $\mathrm{H}_{2}$ is a small molecule that can easily dissipate throughout the body and cells; thus, it may be a safe and effective antioxidant for inflammatory diseases and cancer, since ROS usually initiates tumor progression. Treatment with $\mathrm{H}_{2}$ may involve correction of the oxidative/anti-oxidative imbalance and suppression of inflammatory mediators. Therefore the present review will discuss the anti-inflammatory and anti-tumorigenic action of $\mathrm{H}_{2}$ via $\mathrm{ROS}$.
\end{abstract}

\section{Contents}

1. Introduction

2. $\mathrm{H}_{2}$ usage method

3. ROS in inflammatory disease and cancer

4. Anti-oxidative characteristic of $\mathrm{H}_{2}$

Correspondence to: Professor Yaping Zhu or Professor Xiaowei Xi, Department of Obstetrics and Gynecology, Shanghai General Hospital, Shanghai Jiao Tong University School of Medicine, 100 Haining Road, Shanghai 200080, P.R. China

E-mail: zhuyp63@126.com

E-mail: xixiaowei1966@126.com

Key words: hydrogen, reactive oxygen species, anti-inflammatory, antitumor

\section{Introduction}

Hydrogen $\left(\mathrm{H}_{2}\right)$ occurs safely in the air with a concentration of $<4.7 \%$, and can be used as an inert gas at body temperature. $\mathrm{H}_{2}$ selectively quenches detrimental reactive oxygen species (ROS), and it has become a novel anti-oxidant due to its anti-apoptotic, antioxidant, anti-inflammatory and anti-allergy effects $(1,2)$. ROS increase cell migration and enhance tumor invasion and metastasis (3). Antioxidants have been demonstrated to effectively protect against cell damage, and $\mathrm{H}_{2}$ effectively decreases radicals $(\cdot \mathrm{OH})$ and peroxynitrite $\left(\mathrm{ONOO}^{-}\right)$ in living cells without disrupting the ROS that are involved in normal metabolic oxidation reduction reactions in cell signaling. Therefore, $\mathrm{H}_{2}$ can be used as an anti-inflammatory and anti-tumorigenic agent in clinical practice. The present review focuses on the association between $\mathrm{H}_{2}$ and ROS in inflammatory disease and cancer.

\section{2. $\mathrm{H}_{2}$ usage method}

Inhalation. $\mathrm{H}_{2}$ has capability to penetrate biomembranes and diffuse into the cytosol, mitochondria and nuclei due to its distribution characteristics, including being able to rapidly penetrate vessel walls and being able to dissolve in water or saline (Fig. 1) (4,5). By contrast, the majority of hydrophilic antioxidants cannot penetrate biomembranes and remain on the surface. Inhalation of $\mathrm{H}_{2}$ or the administration of $\mathrm{H}_{2}$ water can increase the concentration of $\mathrm{H}_{2}$ in arterial and venous blood (6).

Oral administration. There are several methods to produce $\mathrm{H}_{2}$ water, including infusing $\mathrm{H}_{2}$ gas into water up to $0.8 \mathrm{mM}$ (1.6 ppm) under atmospheric pressure or dissolving electrolyzed $\mathrm{H}_{2}$ into pure water to form $\mathrm{H}_{2}$ bubbled water. $\mathrm{H}_{2}$ rapidly penetrates the glass and plastic walls of any vessels, but has a half-time of $0-2 \mathrm{~h}$ and almost disappears after $8 \mathrm{~h}$, so aluminum containers with no dead volume are usually used to reserve $\mathrm{H}_{2}$ gas (7).

Intravenous drip. In contrast to $\mathrm{H}_{2}$ gas, $\mathrm{H}_{2}$ saturated in saline (HS) is easy to administer by dissolving $\mathrm{H}_{2}$ in physiological saline for $6 \mathrm{~h}$ under $0.4 \mathrm{MPa}$ pressure to a supersaturated level (8). HS can be stored in an aluminum bag under atmospheric pressure at $4^{\circ} \mathrm{C}$, with a $>0.6 \mathrm{mmol} / \mathrm{l}$ concentration 
of $\mathrm{H}_{2}$ (8). HS can be infused into the stomachs of rats for experimental and clinical treatments $(8,9)$.

Clinical application of $\mathrm{H}_{2}$-enriched glucose-electrolyte solution can be used for acute cerebral infarction and in patients treated with t-PA (9). The solution can be produced at $1.6 \mathrm{ppm}$ $\mathrm{H}_{2}$ concentrations using $\mathrm{H}_{2}$ adding equipment. Administration of $500 \mathrm{ml}$ intravenous $\mathrm{H}_{2}$-enriched fluid over $30 \mathrm{~min}$ for $>3$ days could relieve the associated symptoms of fever and pain in patients with acute erythematous skin diseases, but does not change physiological parameters in the blood (10).

External use. $\mathrm{H}_{2}$ penetrates the skin easily and is distributed throughout the whole body via the blood in $10 \mathrm{~min}$, as measured by $\mathrm{H}_{2}$ gas content in expired breath. Submersion in a warm water bath with dissolved $\mathrm{H}_{2}$ is a method of absorbing $\mathrm{H}_{2}$ into the body in daily life. Hydrogen-water bathing therapy (hydrogen-water was provided by Shanghai Yiquan Investment Limited Partnership Company, Shanghai, China) has a significant and rapid improvement on disease severity and the quality of life for patients with psoriasis and parapsoriasis en plaques (11). Additionally, $\mathrm{H}_{2}$-loaded eye drops can be made by dissolving $\mathrm{H}_{2}$ in saline and can be directly dropped onto the ocular surface $(12,13)$.

\section{ROS in inflammatory disease and cancer}

Cancer is a multi-stage process defined by initiation, promotion and progression (14-16), and oxidative stress interacts with all three stages of this process. ROS can increase tumor cell proliferation, survival and cellular migration in animal models and humans by inducing cellular signal transduction pathways $(17,18)$

What are ROS? ROS are formed as a result of an imbalance between free radical and reactive metabolite production, and can potentially exhibit a negative impact on the organism (19). ROS are products of oxygen-derived small molecules involved in normal cellular metabolism, including oxygen radicals such as superoxide anion $\left(\mathrm{O}_{2}{ }^{-}\right)$, hydroxyl $(\cdot \mathrm{OH})$, peroxyl $\left(\mathrm{RO}_{2}{ }^{\circ}\right)$, and alkoxyl ( $\left.\mathrm{RO}^{\circ}\right)$, as well as non-radicals, which can be converted to radicals or function as oxidizing agents, including $\mathrm{H}_{2}$ peroxide $\left(\mathrm{H}_{2} \mathrm{O}_{2}\right)$, hypochlorous acid $(\mathrm{HOCl})$, ozone $\left(\mathrm{O}_{3}\right)$ and singlet oxygen $\left({ }^{1} \mathrm{O}_{2}\right)$. ROS promote DNA synthesis, cell proliferation, cell survival, cellular migration and invasion, tumor metastasis and angiogenesis (20). Aerobic cells produce ROS, including $\mathrm{O}_{2}{ }^{\circ}, \mathrm{H}_{2} \mathrm{O}_{2}$ and $\cdot \mathrm{OH}$, in endogenous metabolic reactions (21). Mitochondria are constantly exposed to high levels of ROS, which cause mitochondrial DNA damage and increase $\mathrm{O}$ and $\cdot \mathrm{OH}$ levels in cellular apoptosis (2).

Reactive nitrogen species (RNS) are formed from nitrogen-containing oxidants such as nitric oxide (NO). The mitochondrial respiratory chain can generate RNS under hypoxic conditions, while RNS can further generate other reactive species (22), and continuous cellular ROS and RNS generation is now known to be a consequence of numerous factors, including carcinogen exposure, inflammation and mitochondrial respiration (23).

ROS initiate tumor progression. Tumor cells generate ROS more abundantly than normal cells and cause elevated oxidative stress (24). Damage to DNA by ROS is involved in chronic inflammatory diseases and in a wide variety of cancer types, including bladder cancer (25), brain tumors (26), breast cancer (27), cervical cancer (28), gastric cancer (29), liver cancer (30), lung cancer (31), melanoma (32), multiple myeloma (33), leukemia (34), lymphoma (35), oral cancer (36), ovarian cancer (37), pancreatic cancer (38), prostate cancer (39) and sarcoma (40).

ROS can initiate tumorigenicity and subsequent tumor progression by inducing DNA damage (41). Oxidative stress interacts with the initiation, promotion and progression of cancer. During the initiation stage, ROS introduce gene mutations and structural alterations into the DNA and produce DNA damage. In the promotion stage, ROS increase cell proliferation or decrease apoptosis of the initiated cell population by causing abnormal gene expression, blocking cell communication and modifying second-messenger systems. Finally, oxidative stress may add DNA alterations to the initiated cell population and promote cancer progression (42).

Impact of ROS on cancer by regulation of gene expression. ROS serve vital roles in stimulating cell signaling pathways in intra- and extracellular environmental conditions (43), regulating gene mutations, and balancing cell proliferation and apoptosis $(3,44)$. Cancer signaling starts from the hypoxic microenvironment of the autocrine and paracrine elements, including vascular endothelial growth factor, hepatocyte growth factor, hypoxia-inducible factor- $1 \alpha$ (HIF-1 $\alpha)$, NO and $\mathrm{H}_{2} \mathrm{O}_{2}$, which generate a positive feedback loop to hyper-activate the protein kinase $\mathrm{B}$ (Akt) locus. Oxidative stress can activate several transcription factors, including nuclear factor $(\mathrm{NF})-\kappa \mathrm{B}$, activator protein 1, p53, HIF-1 $\alpha$, matrix metalloproteinases, peroxisome proliferator-activated receptor- $\gamma, \beta$-catenin/Wnt and nuclear factor erythroid 2-related factor 2 (Nrf2). These effector molecules are activated under prolonged ROS-related chronic inflammation and alter the malignant transformation and the expression of genes involved in immune, inflammatory responses, carcinogenesis and metastasis.

\section{Anti-oxidative characteristic of $\mathbf{H}_{2}$}

It has been demonstrated that a number of factors, including intense exercise, cardiac infarction (45), cessation of blood flow, organ transplantation and inflammation (46), can cause acute oxidative stress. $\mathrm{H}_{2}$ is able to reduce the risk of life style-related diseases and cancer (7,47-49), and thus can be used to treat various diseases using its characteristic of protecting nuclear DNA and mitochondria.

$\mathrm{H}_{2}$ reduces oxidants in $\mathrm{ROS} . \mathrm{H}_{2}$ dissolved in culture medium selectively reduces the strongest oxidants, such as $\mathrm{OH}$ and $\mathrm{ONOO}^{-}$, in cell signaling, but does not disturb the cellular levels of $\cdot \mathrm{O}_{2}$, $\mathrm{NO} \cdot$ or $\mathrm{H}_{2} \mathrm{O}_{2}$, as well as $\mathrm{ROS}$ involved in metabolic oxidation-reduction reactions in cell-free systems (Fig. 2). As $\cdot \mathrm{OH}$ is strong enough to react with $\mathrm{H}_{2}$, it can be a marker of the oxidative strength of ROS. It was previously reported that $\mathrm{H}_{2}$ treatment significantly reduced $\cdot \mathrm{OH}$ produced by radiolysis or photolysis of water and decreased the levels of $\cdot \mathrm{OH}$ in cultured cells, thus protecting the mitochondria from $\mathrm{OH}(1)$. Since $\mathrm{H}_{2}$ penetrates biomembranes 


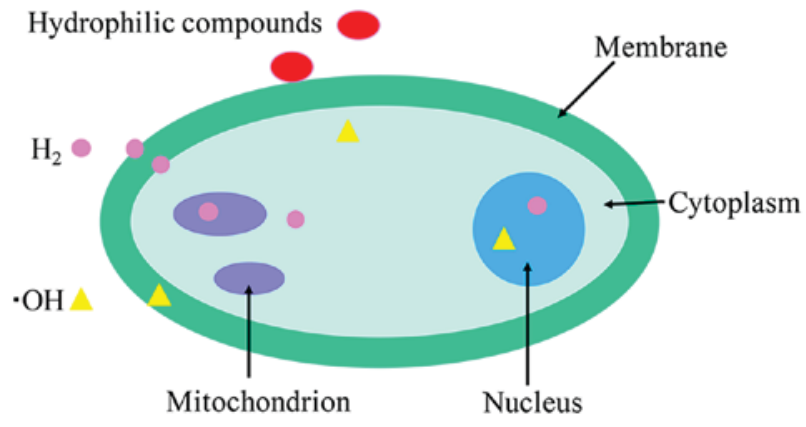

Figure 1. Illustration of $\mathrm{H}_{2}$ diffusion in a cell. The majority of hydrophilic compounds cannot reach the cytosol and remain at the membranes, but $\mathrm{H}_{2}$ can rapidly distribute into the cytosol and organelles. $\mathrm{H}_{2}$, hydrogen.

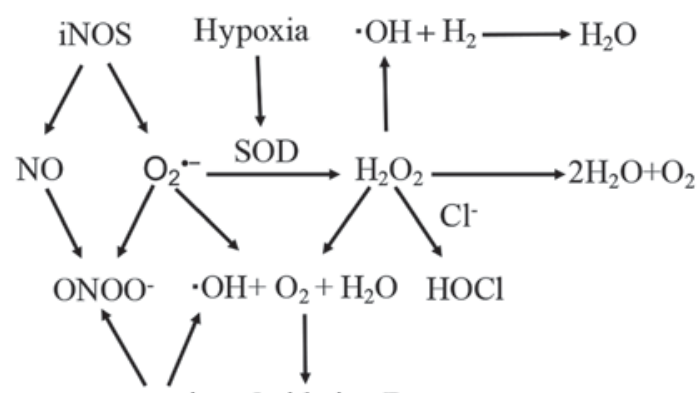

Reactive oxygen species Oxidative Damage

Figure 2. Impact of key oxidants of $\mathrm{H}_{2}$ in cancer: $\cdot \mathrm{OH}$ and $\mathrm{ONOO}^{-}$are highly reactive to damaged cells, while $\cdot \mathrm{O}_{2}, \mathrm{NO} \cdot$ and $\mathrm{H}_{2} \mathrm{O}_{2}$ have physiological roles as signaling molecules. $\mathrm{H}_{2}$, hydrogen; $\mathrm{OH}$, hydroxyl radicals; $\mathrm{ONOO}^{-}$, peroxynitrite; ${ }^{\circ} \mathrm{O}_{2}$, superoxide anion; $\mathrm{NO}$, nitric oxide; $\mathrm{H}_{2} \mathrm{O}_{2}, \mathrm{H}_{2}$ peroxide; $\mathrm{Cl}^{-}$, chloride; $\mathrm{H}_{2} \mathrm{O}$, water; iNOS, inducible nitric oxide synthase; $\mathrm{SOD}$, superoxide dismutase.

and diffuses into organelles, it can decrease cellular levels of ATP synthesized in the mitochondria and nucleus (1). Ren et al (50) demonstrated that treatment with $5 \% \mathrm{H}_{2}$-rich water led to a significant decrease in the level of ROS, maintained the biomass and polar growth morphology of the mycelium, and decreased the secondary metabolism under acetic acid-induced oxidative stress (50). $\mathrm{H}_{2}$ also decreased the levels of ROS and promoted the chronic ultraviolet exposure-induced expression of phosphoinositide 3-kinase, Akt and $\mathrm{Nrf2}$ in $\mathrm{HaCaT}$ cells (51). Since $\mathrm{H}_{2}$ treatment exhibited anti-oxidant and anti-inflammatory neuroprotective effects, it essentially decreased cyclooxygenase-2 (oxidative stress markers) in immune-positive neurons (52).

Anti-inflammatory and antitumor activity of $\mathrm{H}_{2}$. $\mathrm{H}_{2}$ anti-inflammatory and anti-allergic features that function via the induction of inflammatory cytokines and the inhibition of cell signal factors. $\mathrm{H}_{2}$ has been shown to decrease the expression of a number of pro-inflammatory factors, including tumor necrosis factor- $\alpha$ (TNF- $\alpha$ ), interleukin (IL)-6, IL-1 $\beta$, IL-10, IL-12, chemokine ligand 2 (CCL2), intercellular adhesion molecule $1, \mathrm{NF}-\kappa \mathrm{B}$, high mobility group box 1 protein and prostaglandin E2. Furthermore, $\mathrm{H}_{2}$-rich saline reduced serum diamine oxidase, TNF- $\alpha$, IL-1 $\beta$, IL- 6 , tissue malondialdehyde, protein carbonyl and myeloperoxidase activity, and also inhibited pro-apoptotic players, including JNK and caspase-3 $(53,54)$.

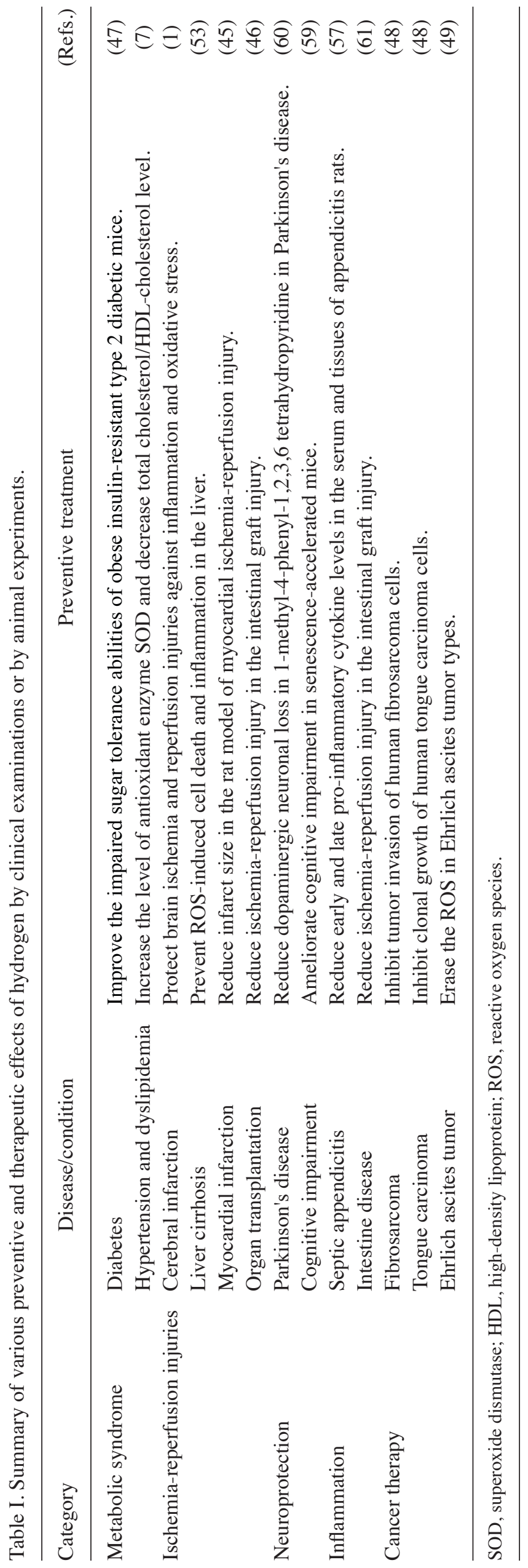


In a previous study, $\mathrm{H}_{2}$ gas inhalation significantly reduced the number of total cells, eosinophils and lymphocytes in the bronchial alveolar lavage fluid, and increased the level of IL-4, IL-13, TNF- $\alpha$ and chemokine (C-X-C motif) ligand 15. The IL-4 serum level was significantly decreased following inhalation. $\mathrm{H}_{2}$ gas inhalation markedly upregulated the activity of superoxide dismutase and significantly attenuated the increased level of malondialdehyde and myeloperoxidase in allergic asthmatic mice (55).

$\mathrm{H}_{2}$ can function as an anti-tumorigenic agent due to its preventive effect against tumor progression and invasion. Accordingly, neutral $\mathrm{pH} \mathrm{H}_{2}$-enriched electrolyzed (NHE) water as an anti-oxidant was previously shown to counteract ROS, inhibiting tumor cell proliferation and invasion together with scavenging of intracellular oxidants. NHE water preferentially inhibited clonal growth of human tongue carcinoma cells, inhibited tumor invasion of human fibrosarcoma cells concurrently with intracellular oxidant repression, and scavenged intracellular oxidant $\mathrm{H}_{2}$ peroxides (48). Additionally, nano-bubble $\mathrm{H}_{2}$ water with platinum colloid is more attractive as a novel antitumor regiment, as it reduces the side effects in normal tissues; it was reported that decreased cell numbers, cell shrinkage, cell apoptosis, cell deformation and microvilli on the membrane surface were observed in Ehrlich ascites tumors, as $\mathrm{H}_{2}$ water erased the ROS that were indispensable for cell growth. These antitumor effects were promoted by combination with hyperthermia at $42^{\circ} \mathrm{C}$ (49) (Table I).

$\mathrm{H}_{2}$ treats disease via an antioxidant effect. In previous studies, the beneficial effects of treatment with $\mathrm{H}_{2}$ on organ damage were associated with decreased oxidative product levels, increased antioxidant enzyme activities, and reduced early and late pro-inflammatory cytokine levels in the serum and tissue. Brain damage followed by cerebral ischemia/reperfusion (I/R) injuries generated ROS, while the antioxidant effect of $\mathrm{H}_{2}$ gas inhalation was able to reduce brain, liver and heart ischemia-reperfusion injury, and intestinal graft injury $(1,45,46,56) . \mathrm{H}_{2}$ protected neurons from ischemia and reperfusion, and was efficacious for cerebral infarction. Furthermore, $\mathrm{H}_{2}$ gas suppressed the progression of hepatic ischemia and reperfusion injury (1). Inhalation of $\mathrm{H}_{2}$ gas significantly lessened the damage to the organs of septic mice with moderate or severe appendicitis by reducing early and late pro-inflammatory cytokine levels in the serum and tissues, thus increasing the survival rate (57).

Ingestion of $\mathrm{H}_{2}$ water can eliminate ROS and confer antitumor activity (48); it represents a novel method of $\mathrm{H}_{2}$ administration and has greater advantages over other forms of antioxidant therapy. Consumption of $\mathrm{H}_{2}$-enriched water has beneficial effects in clinical practice, including the treatment of atherosclerosis, metabolic syndrome, type 2 diabetes, and cognitive impairment during aging and Parkinson's disease (7,47,58-60).

It was previously reported that HS protected brain ischemia and reperfusion injuries against inflammation and oxidative stress, as well as improving function in a neonatal hypoxiaischemia rat model (59). HS prevented early pathological changes in acute hepatic injury and was able to prevent ROS-induced cell death and inflammation in the liver by inhibiting the processes of liver cirrhosis and hepatocyte compensatory proliferation (53). Additionally, HS has protective effects on small intestine ischemia/reperfusion injuries (8). These advantages of HS elucidate the clinical potential for preventive and therapeutic anti-oxidative applications (Table I).

Therapeutic and protective function of $\mathrm{H}_{2}$ in chemotherapy and radiotherapy. Radiotherapy and chemotherapy are major treatment types for cancer. $\mathrm{H}_{2}$ diffuses rapidly to reduce cytotoxic radicals and inflammation in tissues. $\mathrm{H}_{2}$ gas or $\mathrm{H}_{2}$ water has been shown to improve the quality of life (QOL) of patients during chemotherapy via its antioxidant properties. Inhalation of $1 \% \mathrm{H}_{2}$ gas or drinking $\mathrm{H}_{2}$ water alleviated the nephrotoxicity, mortality and body-weight loss caused by cisplatin. Drinking $\mathrm{H}_{2}$ water also decreased the level of apoptosis in the kidney. Despite possessing protective effects against cisplatin-induced toxicity, $\mathrm{H}_{2}$ did not compromise the antitumor effects of cisplatin against cancer cell lines in vitro and in tumor-bearing mice in vivo $(4,61)$.

It was hypothesized that the majority of radiation-induced symptoms associated with increased ROS and inflammation during radiotherapy would significantly affect the patient's QOL (62). The biological reaction to radiation-induced oxidative stress is reduced by the consumption of $\mathrm{H}_{2}$-rich water, without antitumor activities being impaired. In one study, consumption of $\mathrm{H}_{2}$-rich water for 6 weeks during radiotherapy significantly improved the QOL scores of patients with malignant liver tumors, and the levels of reactive oxygen metabolites in the blood were reduced (63).

Overall, $\mathrm{H}_{2}$ reduces the risk of life style-related oxidative stress by reacting with strong reactive oxygen/nitrogen species in cell-free reactions. It is easily to apply $\mathrm{H}_{2}$ in cases of oxidative stress, inflammation and tumors. Due to the lack of adverse effects and the high efficacy for the majority of pathogenic statuses involved, $\mathrm{H}_{2}$ gas, $\mathrm{H}_{2}$ water and $\mathrm{HS}$ are increasingly being accepted as promising candidates for therapeutic approaches. We hypothesize that $\mathrm{H}_{2}$ gas inhalation and oral administration of $\mathrm{H}_{2}$ water could protect against inflammation in oxidative stress-related cancer, and thus improve the antitumor effect in the clinical management of cancer.

\section{References}

1. Ohsawa I, Ishikawa M, Takahashi K, Watanabe M, Nishimaki K, Yamagata K, Katsura K, Katayama Y, Asoh S and Ohta S: Hydrogen acts as a therapeutic antioxidant by selectively reducing cytotoxic oxygen radicals. Nat Med 13: 688-694, 2007.

2. Sato Y, Kajiyama S, Amano A, Kondo Y, Sasaki T, Handa S, Takahashi R, Fukui M, Hasegawa G, Nakamura N, et al: Hydrogen-rich pure water prevents superoxide formation in brain slices of vitamin C-depleted SMP30/GNL knockout mice. Biochem Biophys Res Commun 375: 346-350, 2008.

3. Rojas V, Hirshfield KM, Ganesan S and Rodriguez-Rodriguez L: Molecular characterization of epithelial ovarian cancer: Implications for diagnosis and treatment. Int J Mol Sci 17: pii: E2113, 2016.

4. Nakashima-Kamimura N, Mori T, Ohsawa I, Asoh S and Ohta S: Molecular hydrogen alleviates nephrotoxicity induced by an anti-cancer drug cisplatin without compromising anti-tumor activity in mice. Cancer Chemother Pharmacol 64: 753-761, 2009.

5. James AM,CocheméHMand MurphyMP:Mitochondria-targeted redox probes as tools in the study of oxidative damage and ageing. Mech Ageing Dev 126: 982-986, 2005.

6. Cardinal JS, Zhan J, Wang Y, Sugimoto R, Tsung A, McCurry KR, Billiar TR and Nakao A: Oral hydrogen water prevents chronic allograft nephropathy in rats. Kidney Int 77: 101-109, 2010. 
7. Nakao A, Toyoda Y, Sharma P, Evans M and Guthrie N: Effectiveness of hydrogen rich water on antioxidant status of subjects with potential metabolic syndrome-an open label pilot study. J Clin Biochem Nutr 46: 140-149, 2010.

8. Zheng X, Mao Y, Cai J, Li Y, Liu W, Sun P, Zhang JH, Sun X and Yuan H: Hydrogen-rich saline protects against intestinal ischemia/reperfusion injury in rats. Free Radic Res 43: 478-484, 2009.

9. Nagatani K, Nawashiro H, Takeuchi S, Tomura S, Otani N, Osada H, Wada K, Katoh H, Tsuzuki N and Mori K: Safety of intravenous administration of hydrogen-enriched fluid in patients with acute cerebral ischemia: Initial clinical studies. Med Gas Res 3: 13, 2013.

10. Ono H, Nishijima Y, Adachi N, Sakamoto M, Kudo Y, Nakazawa J, Kaneko K and Nakao A: Hydrogen(H2) treatment for acute erythymatous skin diseases. A report of 4 patients with safety data and a non-controlled feasibility study with $\mathrm{H} 2$ concentration measurement on two volunteers. Med Gas Res 2: 14, 2012.

11. Zhu Q, Wu Y, Li Y, Chen Z, Wang L, Xiong H, Dai E, Wu J, Fan B, Ping L and Luo X: Positive effects of hydrogen-water bathing in patients of psoriasis and parapsoriasis en plaques. Sci Rep 8: 8051, 2018.

12. Kubota M, Shimmura S, Kubota S, Miyashita H, Kato N, Noda K, Ozawa Y, Usui T, Ishida S, Umezawa $\mathrm{K}$, et al: Hydrogen and $\mathrm{N}$-acetyl-L-cysteine rescue oxidative stress-induced angiogenesis in a mouse corneal alkali-burn model. Invest Ophthalmo Vis Sci 52: 427-433, 2011

13. Oharazawa H, Igarashi T, Yokota T, Fujii H, Suzuki H, Machide M, Takahashi H, Ohta S and Ohsawa I: Protection of the retina by rapid diffusion of hydrogen: Administration of hydrogen-loaded eye drops in retinal ischemia-reperfusion injury. Invest Ophthalmol Vis Sci 51: 487-492, 2010.

14. Ames BN and Gold LS: Animal cancer tests and cancer prevention. J Natl Cancer Inst Monogr: 125-132, 1992.

15. Guyton KZ and Kensler TW: Oxidative mechanisms in carcinogenesis. Br Med Bull 49: 523-544, 1993.

16. Schulte-Hermann R, Timmermann-Trosiener I, Barthel G and Bursch W: DNA synthesis, apoptosis, and phenotypic expression as determinants of growth of altered foci in rat liver during phenobarbital promotion. Cancer Res 50 5127-5135, 1990.

17. Trush MA and Kensler TW: An overview of the relationship between oxidative stress and chemical carcinogenesis. Free Radic Biol Med 10: 201-209, 1991

18. Cerutti PA: Prooxidant states and tumor promotion. Science 227 375-381, 1985

19. Duracková Z: Some current insights into oxidative stress. Physiol Res 59: 459-469, 2010.

20. Zhang G, Miura Y and Yagasaki K: Suppression of adhesion and invasion of hepatoma cells in culture by tea compounds through antioxidative activity. Cancer Lett 159: 169-173, 2000.

21. Fridovich I: The biology of oxygen radicals. Science 201 875-880, 1978

22. Hussain SP, Hofseth LJ and Harris CC: Radical causes of cancer Nat Rev Cancer 3: 276-285, 2003.

23. Lei XG, Zhu JH, Cheng WH, Bao Y, Ho YS, Reddi AR, Holmgren A and Arnér ES: Paradoxical roles of antioxidant enzymes: Basic mechanisms and health implications. Physiol Rev 96: 307-364, 2016.

24. Szatrowski TP and Nathan CF: Production of large amounts of hydrogen peroxide by human tumor cells. Cancer Res 51: 794-798, 1991

25. Miyajima A, Nakashima J, Yoshioka K, Tachibana M, Tazaki H and Murai M: Role of reactive oxygen species in cis-dichlorodiammineplatinum-induced cytotoxicity on bladder cancer cells. Br J Cancer 76: 206-210, 1997.

26. Salganik RI, Albright CD, Rodgers J, Kim J, Zeisel SH, Sivashinskiy MS and Van Dyke TA: Dietary antioxidant depletion: Enhancement of tumor apoptosis and inhibition of brain tumor growth in transgenic mice. Carcinogenesis 21: 909-914, 2000.

27. Brown NS and Bicknell R: Hypoxia and oxidative stress in breast cancer. Oxidative stress: Its effects on the growth, metastatic potential and response to therapy of breast cancer. Breast Cancer Res 3: 323-327, 2001.

28. Sharma A, Rajappa M, Satyam A and Sharma M: Oxidant/anti-oxidant dynamics in patients with advanced cervical cancer: Correlation with treatment response. Mol Cell Biochem 341: 65-72, 2010.
29. Oliveira CP, Kassab P, Lopasso FP, Souza HP, Janiszewski M, Laurindo FR, Iriya $\mathrm{K}$ and Laudanna AA: Protective effect of ascorbic acid in experimental gastric cancer: Reduction of oxidative stress. World J Gastroenterol 9: 446-448, 2003.

30. Calvisi DF, Ladu S, Hironaka K, Factor VM and Thorgeirsson SS: Vitamin E down-modulates iNOS and NADPH oxidase in c-Myc/TGF-alpha transgenic mouse model of liver cancer. J Hepatol 41: 815-822, 2004.

31. Azad N, Rojanasakul Y and Vallyathan V: Inflammation and lung cancer: Roles of reactive oxygen/nitrogen species. J Toxicol Environ Health B Crit Rev 11: 1-15, 2008.

32. Fruehauf JP and Trapp V: Reactive oxygen species: An Achilles heel of melanoma? Expert Rev Anticancer Ther 8: 1751-1757, 2008

33. Kuku I, Aydogdu I, Bayraktar N, Kaya E, Akyol O and Erkurt MA: Oxidant/antioxidant parameters and their relationship with medical treatment in multiple myeloma. Cell Biochem Funct 23: 47-50, 2005

34. Sumi D, Shinkai Y and Kumagai Y: Signal transduction pathways and transcription factors triggered by arsenic trioxide in leukemia cells. Toxicol Appl Pharmacol 244: 385-392, 2010.

35. van de Wetering CI, Coleman MC, Spitz DR, Smith BJ and Knudson CM: Manganese superoxide dismutase gene dosage affects chromosomal instability and tumor onset in a mouse model of T cell lymphoma. Free Radic Biol Med 44: 1677-1686, 2008.

36. Bahar G, Feinmesser R, Shpitzer T, Popovtzer A and Nagler RM: Salivary analysis in oral cancer patients: DNA and protein oxidation, reactive nitrogen species, and antioxidant profile. Cancer 109: 54-59, 2007.

37. Chan DW, Liu VW, Tsao GS, Yao KM, Furukawa T, Chan KK and Ngan HY: Loss of MKP3 mediated by oxidative stress enhances tumorigenicity and chemoresistance of ovarian cancer cells. Carcinogenesis 29: 1742-1750, 2008.

38. Wang M, Topalovski M, Toombs JE, Wright CM, Moore ZR, Boothman DA, Yanagisawa $\mathrm{H}$, Wang $\mathrm{H}$, Witkiewicz A, Castrillon DH and Brekken RA: Fibulin-5 blocks microenvironmental ROS in pancreatic cancer. Cancer Res 75: 5058-5069, 2015.

39. Shan W, Zhong W, Swanlund J and Oberley TD. Oxidative stress in prostate cancer. Oxidative Stress Cancer Biol Ther: pp301-331, 2011.

40. Ma Q, Cavallin LE, Yan B, Zhu S, Duran EM, Wang H, Hale LP, Dong C, Cesarman E, Mesri EA and Goldschmidt-Clermont PJ: Antitumorigenesis of antioxidants in a transgenic Rac1 model of Kaposi's sarcoma. Proc Natl Acad Sci USA 106: 8683-8688, 2009.

41. Wang J and Yi J: Cancer cell killing via ROS: To increase or decrease, that is the question. Cancer Biol Ther 7: 1875-1884, 2008.

42. Klaunig JE, Xu Y, Isenberg JS, Bachowski S, Kolaja KL, Jiang J, Stevenson DE and Walborg EF Jr: The role of oxidative stress in chemical carcinogenesis. Environ Health Perspect 106 (Suppl 1): S289-S295, 1998.

43. Jabs T: Reactive oxygen intermediates as mediators of programmed cell death in plants and animals. Biochem Pharmacol 57: 231-245, 1999.

44. Roos WP, Thomas AD and Kaina B: DNA damage and the balance between survival and death in cancer biology. Nat Rev Cancer 16: 20-33, 2016

45. Hayashida K, Sano M, Ohsawa I, Shinmura K, Tamaki K, Kimura K, Endo J, Katayama T, Kawamura A, Kohsaka S, et al: Inhalation of hydrogen gas reduces infarct size in the rat model of myocardial ischemia-reperfusion injury. Biochem Biophys Res Commun 373: 30-35, 2008.

46. Buchholz BM, Kaczorowski DJ, Sugimoto R, Yang R, Wang Y, Billiar TR, McCurry KR, Bauer AJ and Nakao A: Hydrogen inhalation ameliorates oxidative stress in transplantation induced intestinal graft injury. Am J Transplant 8: 2015-2024, 2008.

47. Shirahata S, Hamasaki T, Haramaki K, Nakamura T, Abe M, Yan H, Kinjo T, Nakamichi N, Kabayama S and Teruya K: Anti-diabetes effect of water containing hydrogen molecule and Pt nanoparticles. BMC Proc 5 (Suppl 8): P18, 2011.

48. Saitoh Y, Okayasu H, Xiao L, Harata Y and Miwa N: Neutral $\mathrm{pH}$ hydrogen-enriched electrolyzed water achieves tumor-preferential clonal growth inhibition over normal cells and tumor invasion inhibition concurrently with intracellular oxidant repression. Oncol Res 17: 247-255, 2008.

49. Asada R, Kageyama K, Tanaka H, Matsui H, Kimura M, Saitoh Y and Miwa N: Antitumor effects of nano-bubble hydrogen-dissolved water are enhanced by coexistent platinum colloid and the combined hyperthermia with apoptosis-like cell death. Oncol Rep 24: 1463-1470, 2010 
50. Ren A, Liu R, Miao ZG, Zhang X, Cao PF, Chen TX, Li CY, Shi L, Jiang AL and Zhao MW: Hydrogen-rich water regulates effects of ROS balance on morphology, growth and secondary metabolism via glutathione peroxidase in Ganoderma lucidum. Environ Microbiol 19: 566-583, 2017.

51. Zhang B, Zhao Z, Meng X, Chen H, Fu G and Xie K: Hydrogen ameliorates oxidative stress via PI3K-Akt signaling pathway in UVB-induced HaCaT cells. Int J Mol Med 41: 3653-3661, 2018.

52. Varga V, Németh J, Oláh O, Tóth-Szűki V, Kovács V, Remzső G and Domoki F: Molecular hydrogen alleviates asphyxia-induced neuronal cyclooxygenase-2 expression in newborn pigs. Acta Pharmacol Sin, 22 Mar 2018 (Epub ahead of print).

53. Sun H, Chen L, Zhou W, Hu L, Li L, Tu Q, Chang Y, Liu Q, Sun X, Wu M and Wang H: The protective role of hydrogen-rich saline in experimental liver injury in mice. J Hepatol 54: 471-480, 2011

54. Hattori Y, Kotani T, Tsuda H, Mano Y, Tu L, Li H, Hirako S, Ushida T, Imai K, Nakano T, et al: Maternal molecular hydrogen treatment attenuates lipopolysaccharide-induced rat fetal lung injury. Free Radic Res 49: 1026-1037, 2015.

55. Zhang N, Deng C, Zhang X, Zhang J and Bai C: Inhalation of hydrogen gas attenuates airway inflammation and oxidative stress in allergic asthmatic mice. Asthma Res Pract 4: 3, 2018.

56. Fukuda K, Asoh S, Ishikawa M, Yamamoto Y, Ohsawa I and Ohta S: Inhalation of hydrogen gas suppresses hepatic injury caused by ischemia/reperfusion through reducing oxidative stress. Biochem Biophys Res Commun 361: 670-674, 2007.
57. Xie K, Yu Y, Pei Y, Hou L, Chen S, Xiong L and Wang G: Protective effects of hydrogen gas on murine polymicrobial sepsis via reducing oxidative stress and HMGB1 release. Shock 34: 90-97, 2010.

58. Ohsawa I, Nishimaki K, Yamagata K, Ishikawa M and Ohta S: Consumption of hydrogen water prevents atherosclerosis in apolipoprotein E knockout mice. Biochem Biophys Res Commun 377: 1195-1198, 2008.

59. Gu Y, Huang CS, Inoue T, Yamashita T, Ishida T, Kang KM and Nakao A: Drinking hydrogen water ameliorated cognitive impairment in senescence-accelerated mice. J Clin Biochem Nutr 46: 269-276, 2010.

60. Fujita K, Seike T, Yutsudo N, Ohno M, Yamada H, Yamaguchi H, Sakumi K, Yamakawa Y, Kido MA, Takaki A, et al: Hydrogen in drinking water reduces dopaminergic neuronal loss in the 1-methyl-4-phenyl-1,2,3,6-tetrahydropyridine mouse model of Parkinson's disease. PLoS One 4: e7247, 2009.

61. Kitamura A,Kobayashi S, Matsushita T, Fujinawa H and Murase K: Experimental verification of protective effect of hydrogen-rich water against cisplatin-induced nephrotoxicity in rats using dynamic contrast-enhanced CT. Br J Radiol 83: 509-514, 2010.

62. Zhao W and Robbins ME: Inflammation and chronic oxidative stress in radiation-induced late normal tissue injury: Therapeutic implications. Curr Med Chem 16: 130-143, 2009.

63. Kang KM, Kang YN, Choi IB, Gu Y, Kawamura T, Toyoda Y and Nakao A: Effects of drinking hydrogen-rich water on the quality of life of patients treated with radiotherapy for liver tumors. Med Gas Res 1: 11, 2011. 